\title{
Diets and Seasonal Ingestion Rates of Aurelia coerulea (Cnidaria: Scyphozoa) Polyps by in situ Feeding Experiments in Jiaozhou Bay, China
}

\section{OPEN ACCESS}

Edited by:

Stelios Katsanevakis,

University of the Aegean, Greece

Reviewed by:

Maria Pia Miglietta,

Texas A\&M University at Galveston,

United States

Cathy Lucas,

University of Southampton,

United Kingdom

*Correspondence:

Zhang Fang

zhangfang@qdio.ac.cn

Sun Song

sunsong@qdio.ac.cn

Specialty section: This article was submitted to

Marine Ecosystem Ecology,

a section of the journal

Frontiers in Marine Science

Received: 17 July 2021

Accepted: 26 August 2021

Published: 23 September 2021

Citation:

Pengpeng W, Fang Z, Dongjie G and Song S (2021) Diets

and Seasonal Ingestion Rates

of Aurelia coerulea (Cnidaria: Scyphozoa) Polyps by in situ Feeding Experiments in Jiaozhou Bay, China.

Front. Mar. Sci. 8:742999.

doi: 10.3389/fmars.2021.742999

\author{
Wang Pengpeng ${ }^{1,2,3}$, Zhang Fang ${ }^{1,2,3,4 *}$, Guo Dongjie ${ }^{1,2,3,4}$ and Sun Song ${ }^{1,2,3,4,5 *}$
}

${ }^{1}$ CAS Key Laboratory of Marine Ecology and Environmental Sciences, Institute of Oceanology, Chinese Academy of Sciences, Qingdao, China, ${ }^{2}$ Laboratory of Marine Ecology and Environmental Sciences, Qingdao National Laboratory for Marine Science and Technology, Qingdao, China, ${ }^{3}$ Center for Ocean Mega-Science, Chinese Academy of Sciences (CAS), Qingdao, China, ${ }^{4}$ College of Marine Science, University of Chinese Academy of Sciences, Qingdao, China, ${ }^{5}$ Jiaozhou Bay Marine Ecosystem Research Station, Institute of Oceanology, Chinese Academy of Sciences (CAS), Qingdao, China

The benthic scyphopolyp population is an important stage in the scyphozoan lifecycle. Nevertheless, few studies have detailed the natural feeding and quantified the energy flux of polyps based on field research. To better understand the scyphopolyp natural diet and seasonal variation patterns in the ingestion rate, in situ feeding experiments were conducted on Aurelia coerulea polyps in Jiaozhou Bay, China from August 2018 to April 2019. The diet of $A$. coerulea polyps was determined by gut content analysis. Digestion rates were also measured. Ingestion rates, based on the gut contents and digestion rates, were assessed monthly. Copepods, copepod nauplii, and ciliates were identified in the guts of $A$. coerulea polyps. Copepods with the bulk of total prey intake in number are an important source of nutrition for $A$. coerulea polyps in Jiaozhou Bay. Prey capture of $A$. coerulea polyps (prey polyp ${ }^{-1}$ ) varied among months, and was highly dependent upon the abundance of planktonic prey in the habitat. Copepods and copepod nauplii were digested more rapidly as temperature increased. Carbon weightspecific ingestion rate exhibited an obvious seasonal change, with the mean value of $0.13 \pm 0.12 \mu \mathrm{g} \mathrm{C} \mu \mathrm{g} \mathrm{C} \mathrm{C}^{-1} \mathrm{~d}^{-1}$. More rapid digestion of prey at higher temperatures and larger prey availability would cause a higher ingestion rate in polyps. Scyphopolyps are widely distributed predators in littoral ecosystems and they may play an important role in plankton-benthos coupling by transferring energy from the water column to the benthos. Massive scyphopolyps blooms may influence pelagic ecosystems.

Keywords: jellyfish bloom, Scyphozoa, feeding, scyphopolyp, Copepoda, prey capture, pelagic ecosystem

\section{INTRODUCTION}

Interest in the importance of jellyfish in the material cycle and the energy flow of marine ecosystems has increased as outbreaks of jellyfish populations attract public and scientific attention (Dong et al., 2010; Uye, 2011; Condon et al., 2013; Duarte et al., 2013). Previous studies have reported the potential causes and consequences of jellyfish population fluctuations, focusing on the trophic relationships between the pelagic medusae and other marine organisms, as well as the effects of medusae blooms on marine ecosystems (Olesen et al., 1994; Purcell, 2003, 2009). Most jellyfish are important as gelatinous consumers of zooplankton and ichthyoplankton, and massive aggregation of pelagic medusae have 
been shown to decrease populations of zooplankton as well as fish eggs and larvae (Schneider and Behrends, 1994; Purcell, 1997; Hansson et al., 2005; Uye, 2011).

Common bloom jellyfish, Aurelia spp., are offshore scyphomedusae with worldwide distributions (Olesen et al., 1994; Purcell et al., 2009; Dong et al., 2010). Mass occurrences of Aurelia medusae have been reported from many parts of the world (Möller, 1980; Olesen et al., 1994; Omori et al., 1995; Dong et al., 2010). This jellyfish has metagenic life cycles, with pelagic stages (ephyra, medusa, and planula) and benthic stages (polyp, strobila, and podocyst) (Arai, 1997; Lucas et al., 2012). The benthic polyps can generate additional polyps through asexual reproduction and release abundant ephyrae (small medusae) by strobilation. Thus, the polyp is an important stage in the Aurelia lifecycle (Lucas et al., 2012) and recruitment success is critical for maintaining jellyfish population (Gröndahl, 1988b; Lucas, 2001; Purcell, 2007). For polyp ecology of the jellyfish Aurelia, previous studies have documented the metamorphosis of planula larvae into polyps, the expansion of polyp via asexual propagation, and the strobilation and recruitment of polyps of this jellyfish under laboratory conditions (e.g., Purcell, 2007; Han and Uye, 2010; Wang N. et al., 2015). The majority of field studies have been confined to the population dynamics and locations of polyp, the timing and rate of strobilation, and the substrates of polyp colonization (e.g., Lucas and Williams, 1994; Uye and Shimauchi, 2005; Purcell et al., 2009; Ishii and Katsukoshi, 2010; Feng et al., 2017).

However, the relative importance of food conditions for natural polyp population is controversial, and few data exist on potential seasonal variation in ingestion rates in situ (Lucas et al., 2012; Ikeda et al., 2017). Previous studies have shown that scyphozoan polyps consume a wide variety of prey, including copepods, copepod nauplii, rotifers, planula larvae of scyphomedusae, dinoflagellates, ciliates, and fish larvae (Gröndahl, 1988b; Östman, 1997; Kamiyama, 2011; Huang et al., 2015; Ikeda et al., 2017). Kamiyama (2011) estimated the feeding rates of Aurelia aurita polyps on ciliates as prey and speculated that planktonic ciliates likely serve as a major food for A. aurita polyps. In contrast, Ikeda et al. (2017) speculated that the most appropriate prey for polyps might be large copepod nauplii by examining the effect of prey characters on the ingestion rate of A. aurita polyps. They also constructed an energy budget model for A. aurita polyp and estimated the ingestion rates of polyps based on the biomass of mesozooplankton in Fukuyama Harbor, Japan. However, most studies on the feeding ecology of polyps have been laboratory-based. Few studies have detailed the natural feeding and quantified the energy flux of polyps based on field research (Mills, 2001; Lucas et al., 2012; Ikeda et al., 2017). Thus, quantitative descriptions of the natural diets and the potential seasonal variation patterns in ingestion rate of Aurelia polyps based on the field research are needed to characterize the feeding ecology of polyps in littoral benthic communities.

Aurelia coerulea blooms have also been reported in Jiaozhou Bay, China (Wan and Zhang, 2012; Wang et al., 2020). In this study, we performed in situ feeding experiments on A. coerulea polyps in Jiaozhou Bay from August 2018 to April 2019. This location provided a natural environment for the prey capture of A. coerulea polyps. Moreover, according to previous studies, strobilation of $A$. coerulea polyps, as indicated by the presence of ephyrae, occurs in Jiaozhou Bay as early as April (Wan and Zhang, 2012; Wang Y. T. and Sun, 2015); A. coerulea attain sexual maturity by mid-summer, and Wang Y. T. and Sun (2015) speculated that the metamorphosis of planula larvae into polyps might occur during August. Therefore, feeding ecology assessments of the $A$. coerulea polyp are most reasonable between August 2018 and April 2019 in Jiaozhou Bay. This covers the period from $A$. coerulea spawning to polyp strobilation. To estimate the diet of polyps in nature, prey types were identified based on gut content analysis. Additionally, we estimated polyp prey digestion rates. Consequently, seasonal variation patterns in polyp ingestion rates were estimated based on in situ surveys of prey abundance in gut contents and digestion rates. Finally, we used the study data to practically assess the potential role of scyphopolyp predators in the plankton-benthos energy transfer process within the littoral ecosystem.

\section{MATERIALS AND METHODS}

\section{Study Area}

Jiaozhou Bay is a semi-enclosed bay located on the southern side of the Shandong Peninsula, China (Figures 1A,B). Jiaozhou Bay is strongly influenced by human activities; industrial and agricultural businesses are found around the bay. Anthropogenic structures in Jiaozhou Bay, such as port installations and offshore platforms, are suitable settling surfaces for scyphopolyps, and the increasing numbers of these anthropogenic structures have provided new habitats (Miyake et al., 2002; Holst and Jarms, 2007). Underwater surveys have identified A. coerulea polyps on the bottom of a research vessel (the "Haiou" boat at the Station) in Jiaozhou Bay (Feng et al., 2017). To better understand the scyphopolyp diet and seasonal variation in ingestion rate in the field, in situ feeding experiments were conducted on A. coerulea polyps in Jiaozhou Bay between August 2018 and April 2019 next year; this provides a realistic environment for the prey capture of polyps.

\section{Temperature, Salinity, and Zooplankton}

Temperature and salinity at 2-3 $\mathrm{m}$ depth (the depth where base plates carrying the polyps were submerged, see below) were measured monthly using an AAQ1183-1F CTD (Alec Electronics Co., Japan) at the station in Jiaozhou Bay. Zooplankton samples were also collected monthly to study plankton variation concurrent with polyp analysis using a II plankton net (mesh size: $160 \mu \mathrm{m}$, diameter: $50 \mathrm{~cm}$ ). The plankton nets were towed a short distance (ca. $30-50 \mathrm{~cm}$ ) from the polyp-settling plastic plates. Zooplankton samples were stored in $5 \%$ formalin in $1-\mathrm{L}$ bottles, classified into different taxonomic groups, and counted. The abundance of each zooplankton group $\left(A\right.$, ind $\left.\mathrm{m}^{-3}\right)$ was determined on a per unit volume $\left(\mathrm{m}^{3}\right)$.

\section{In situ Experiment Procedures and Sampling}

Aurelia coerulea polyps were obtained by previously described artificial asexual reproduction methods (Holst and Jarms, 2007; 


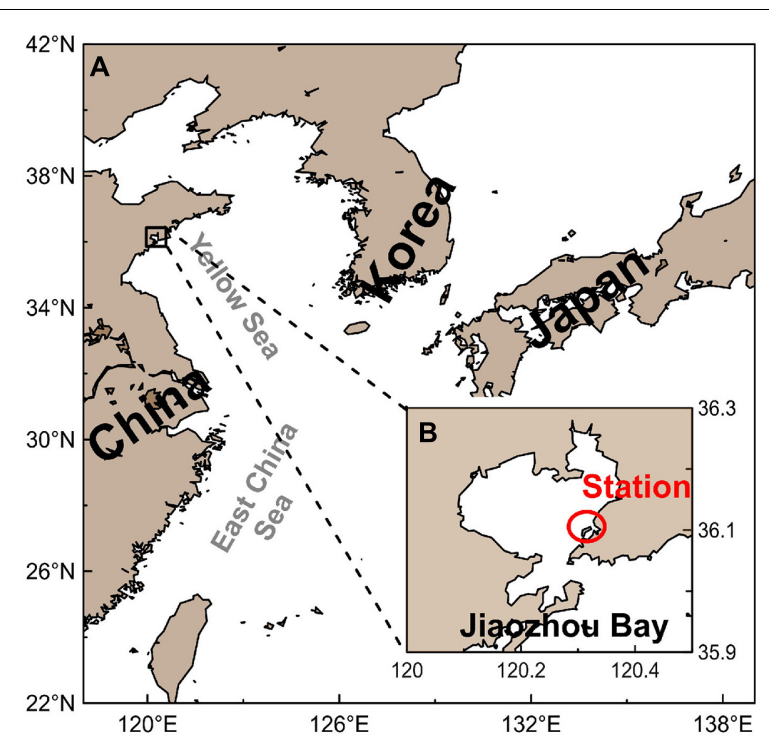

C

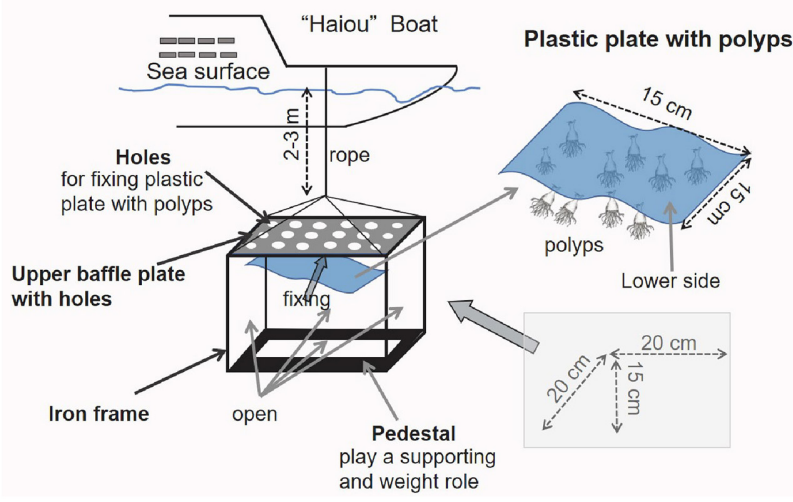

FIGURE 1 | Study area and schematic diagram of Aurelia coerulea polyps in situ feeding experiment. (A) Map of Jiaozhou Bay. (B) Station in Jiaozhou Bay where the plastic plates carrying polyps were deployed. (C) A roof ( $20 \mathrm{~cm} \times 20 \mathrm{~cm} \times 15 \mathrm{~cm}$ ) with four open sides was used to support the plastic plate carrying the polyps; the upper side was a baffle plate to simulate the bottom of "Haiou" boat, and the holes were used to fix plastic plate and tie a rope; the lower side was a pedestal that played a supporting and weight role. Polyps were attached to the lower side of the plastic plate $(15 \mathrm{~cm} \times 15 \mathrm{~cm})$

Feng et al., 2017). Six mature females and four mature males (A. coerulea medusae) collected in Jiaozhou Bay were cultured in a $200-\mathrm{L}$ aquarium at a water temperature of $21-23^{\circ} \mathrm{C}$ in our jellyfish laboratory (Institute of Oceanology, Chinese Academy of Sciences). Corrugated plastic plates $(15 \mathrm{~cm} \times 15 \mathrm{~cm})$ were deployed as bases for A. coerulea polyp attachment. Before in situ experiments, these polyps were cultured in 120-L aquariums filled with filtered seawater $(20-\mu \mathrm{m}$ filter $)$ at a water temperature of $21-23^{\circ} \mathrm{C}$ and salinity of $31-32$. Adequate Artemia nauplii were supplied daily $\left(7 \times 10^{3}\right.$ ind $\left.\mathrm{L}^{-1}\right)$, and the water was then replaced with newly filtered seawater. Fully developed 16-tentacle polyps were selected for the following in situ feeding experiments between August 2018 and April 2019. Although the experimental polyp ages after asexual reproduction were different between different months, the sizes of polyps (calyx diameter, $\mu \mathrm{m}$ ) used for in situ experiments were similar between different months (the mean size of polyps for the following gut contents across 9 months was $965.86 \pm 289.50 \mu \mathrm{m})$.

A floating dock, the "Haiou" boat (50-m long, 8-m wide) in Jiaozhou Bay $\left(36.07^{\circ} \mathrm{N}, 120.34^{\circ} \mathrm{E}\right)$, was used as the experimental platform. The water depths ranged between 5 and $6 \mathrm{~m}$ at the station. Before deployment, each plastic plate carrying polyps was fixed on a roof with four open sides (20-cm long, 20$\mathrm{cm}$ wide, $15-\mathrm{cm}$ high, Figure $1 \mathrm{C}$ ) to support the plastic plate and to reduce possible physical damage caused by movements. The polyps were then acclimated for at least $48 \mathrm{~h}$ with the in situ filtered seawater (20- $\mu \mathrm{m}$ filter) before the experiments. The A. coerulea polyps used for the in situ feeding experiments appeared healthy, extending tentacles fully. Each month (from August 2018 to April 2019), five base plates carrying the polyps (mean density was about 3 polyps $\mathrm{cm}^{-2}$ ) were submerged at the station and secured by ropes at a depth of 2-3 $\mathrm{m}$, and the mean size of polyps was similar between different base plates. Five new plastic plates were deployed in the next month following the above processes. The rooves carrying plastic plates were all horizontally moored with the polyps' attachment side facing downward (Figure 1C), mimicking the natural state in Jiaozhou Bay and avoiding sedimentation effects (Feng et al., 2017).

All samplings for gut content analysis were conducted during the day (8:00 a.m. to 6:00 p.m.), and the seasonal variations in the gut contents of $A$. coerulea polyps sampled diurnally were compared. The plastic plates with polyps were sampled a minimum of 15 days after deployment to ensure that polyps were adequately acclimated to the field environment. Before polyp sampling, the rooves carrying the plates were slowly pulled out (pulling speed no more than $0.1 \mathrm{~m} \mathrm{~s}^{-1}$ ). A bucket $(40-\mathrm{cm}$ diameter, $32-\mathrm{cm}$ high) was used to take the rooves out when the rooves were about to leave the water. Polyps were divided into two parts: one part was sampled for gut content analysis, and the other part was used for the digestion experiment (see below).

\section{Gut Content Analysis and Estimation of Prey Carbon Content}

Gut contents of polyps were analyzed monthly. A total of 50 visually undamaged polyps from one plastic plate were randomly collected for gut content analysis each month. The selected plate carrying the polyps was cut with scissors. Then they were immediately placed in a glass Petri dish (9-cm in diameter) with $5 \%$ buffered formaldehyde to prevent further digestion. The polyps' attachment side faced upward to protect these polyps from damage. The sampled polyps were immediately examined under a stereo microscope (Nikon Corporation, Shinagawa-ku, Tokyo, Japan). At the same time, the sizes of these polyps (calyx diameter, $\mu \mathrm{m}$ ) were measured by the NIS-Elements $\mathrm{D}$ software (Ver. 5.01). The waters in the Petri dishes for the preservation of polyps were also checked. Prey items including copepods (including copepod adults and copepodites), copepod nauplii, and ciliates (Tintinnids) were identified in polyps' guts. Crustacean carapaces and tentacles were also found in polyps' 
guts. Each prey item was enumerated. The numbers of polyps with prey in the gut were also recorded.

The mean carbon contents of copepods and copepod nauplii found in the guts of polyps were estimated by volume biomass of prey referring to the methods described by previous studies (Table 1). The copepods and copepod nauplii isolated from polyps' guts were selected to measure the lengths (prosome length for copepods and carapace length for copepod nauplii) by the NIS-Elements D software. Then, the mean carbon contents of copepods and copepod nauplii captured by polyps were determined by methods used in the studies of Uye (1982) and Berggreen et al. (1988), respectively (Table 1).

\section{Digestion Experiments}

Polyp digestion rates were determined by examining the decrease in the number of prey in polyps' guts over time (h). Digestion rates of copepods were measured monthly by in situ experiments. However, it was impossible to determine how long prey had been in the gut prior to sampling. Therefore, we assumed that copepods were captured by the polyps shortly before collection. Polyps for digestion experiments were collected from 2 to 5 plates, depending on the digestion rates and sampling times during experiments in different months. The base plates carrying polyps for the digestion experiments were dipped in a $50-\mathrm{L}$ container with natural filtered seawater $(20-\mu \mathrm{m}$ filter $)$. The time when the base plates were transferred to the container was considered as the initial time. To follow the digestion process, 50 visually undamaged polyps (16-tentacle) were collected per hour, and the selected polyps were immediately preserved in a glass Petri dish with 5\% buffered formaldehyde to stop digestion. Then the selected polyps were dissected under a stereo microscope and the remaining numbers of copepods in polyp guts at each sampling time were recorded. The length of time at which no prey could be detected (the solid matter and tissues of prey disappeared or only carapaces and tentacles were left, the ending time) was used in the calculation of the following prey-capture rates (Martinussen and Båmstedt, 1999; Purcell, 2003).

Gut content analysis indicated that polyps' guts contained a small number of copepod nauplii at the start of the digestion experiments; therefore, the digestion rate of copepod nauplii could not be measured directly in situ, but under laboratory conditions. Copepod nauplii (mean carapace length:

TABLE 1 | Estimation of carbon weight of different prey items (copepods and copepod nauplii) found in the gut of polyp.

\begin{tabular}{|c|c|c|c|c|}
\hline Prey & $\begin{array}{l}\text { Body length }(L, \\
\text { mean } \pm S D, \mu \mathrm{m})\end{array}$ & $n$ & $\begin{array}{c}\text { Carbon } \\
\text { weight }(C, \mu g)\end{array}$ & References \\
\hline Copepod & $485.47 \pm 134.34^{a}$ & 112 & 0.750 & Uye, $1982^{c}$ \\
\hline $\begin{array}{l}\text { Copepod } \\
\text { nauplii }\end{array}$ & $237.96 \pm 45.13^{b}$ & 24 & 0.234 & $\begin{array}{l}\text { Berggreen } \\
\text { et al., 1988 }\end{array}$ \\
\hline $\begin{array}{l}\text { " } n \text { " means the } \\
\text { measurement of b } \\
\text { a Prosome length. } \\
{ }^{b} \text { Carapace length. } \\
{ }^{c} \text { Calculated using } \\
{ }^{d} \text { Calculated using }\end{array}$ & $\begin{array}{l}\text { numbers of pre } \\
\text { ody length. } \\
\log C=3.07 \log L-8 \\
C=3.18 \times 10^{-9} \times\end{array}$ & in & polyps guts & cted for the \\
\hline
\end{tabular}

$204.7 \mu \mathrm{m}$ ) were obtained by the reproduction of mature copepods (Pseudodiaptomus annandalei, Calanoida) cultured in our laboratory at a water temperature of about $21^{\circ} \mathrm{C}$ and salinity of 31-32, and two diatoms, Phaeodactylum tricornutum and Chrysophyta, were offered as prey for copepods daily. Before experiments, copepod nauplii (about 500 ind $\mathrm{L}^{-1}$ ) were offered as prey for polyps feeding for about $0.5-1 \mathrm{~h}$ (mean 1.2 prey polyp $^{-1}$ after feeding). Then these polyps were transferred into filtered seawater $(20-\mu \mathrm{m}$ filter) and were cultured in constanttemperature incubators. To study the effect of temperature on digestion rates, digestion experiments were conducted in constant-temperature incubators at $5,7,12,18,22$, and $26^{\circ} \mathrm{C}$ (according to the natural temperatures), respectively. A total of 20 polyps were collected per hour, and the selected polyps were immediately preserved in $5 \%$ buffered formaldehyde. They were then dissected under a stereo microscope to follow the digestion process.

We did not measure the digestion rate of ciliate due to the difficulty in detecting the variation in the number of ciliates in polyp gut over time by laboratory test.

\section{Prey Capture and Ingestion Rate}

The mean number of copepods and copepod nauplii found in the gut of each sampled polyp (50 polyp specimens on each sampling date) was recorded as prey capture $\left(N\right.$, prey polyp $\left.{ }^{-1}\right)$. The preycapture rate $(C)$ of $A$. coerulea polyp was expressed as the number of prey captured per polyp per day (prey polyp ${ }^{-1} \mathrm{~d}^{-1}$ ) and was calculated monthly following Coma et al. (1994):

$$
C=N\left[\sum_{t=0}^{D} 1-(t / D)\right]^{-1} \times 24
$$

where $t$ is time (in hours), and $D$ is the digestion time (in hours).

Then the ingestion rate of polyp $\left(I, \mu g \mathrm{C}_{\text {polyp }}{ }^{-1} \mathrm{~d}^{-1}\right)$ was calculated based on the carbon content weight of copepods and copepod nauplii ( $P W, \mu \mathrm{g} C$; Table 1). However, differences in the size of polyps collected on the same sampling date may affect the prey capture of polyps. To eliminate the effect of polyp size on ingestion rate, we converted polyp size to polyp carbon weight ( $W, \mu \mathrm{g} C$ ) using the relationship between polyp body volume $\left(B V, \mu \mathrm{m}^{3}\right)$ and carbon weight as given in Ikeda et al. (2017): $W=$ $B V \times 27.4 \times 10^{-9}$. The contracted polyps were photographed with a digital camera-equipped stereo microscope to determine their body volumes (Ikeda et al., 2017). The ingestion rates were converted to carbon weight-specific ingestion rates $\left(I_{w}, \mu \mathrm{g} \mathrm{C} \mu \mathrm{g}\right.$ $\mathrm{C}^{-1} \mathrm{~d}^{-1}$; copepods and copepods nauplii as prey): $I_{W}=I / W$.

\section{Statistical Analyses}

OriginPro8.0 and SPSS16.0 were used to organize and statistically analyze the data in this study. One-way analysis of variance (ANOVA) was used to determine the differences in polyp size for gut content analysis and digestion rate on different sampling dates; normality and equal variances were checked before ANOVA analysis. The Spearman correlation test was used to evaluate the relationship between both the number of polyps with prey in gut and prey capture (prey polyp ${ }^{-1}$ ) and 


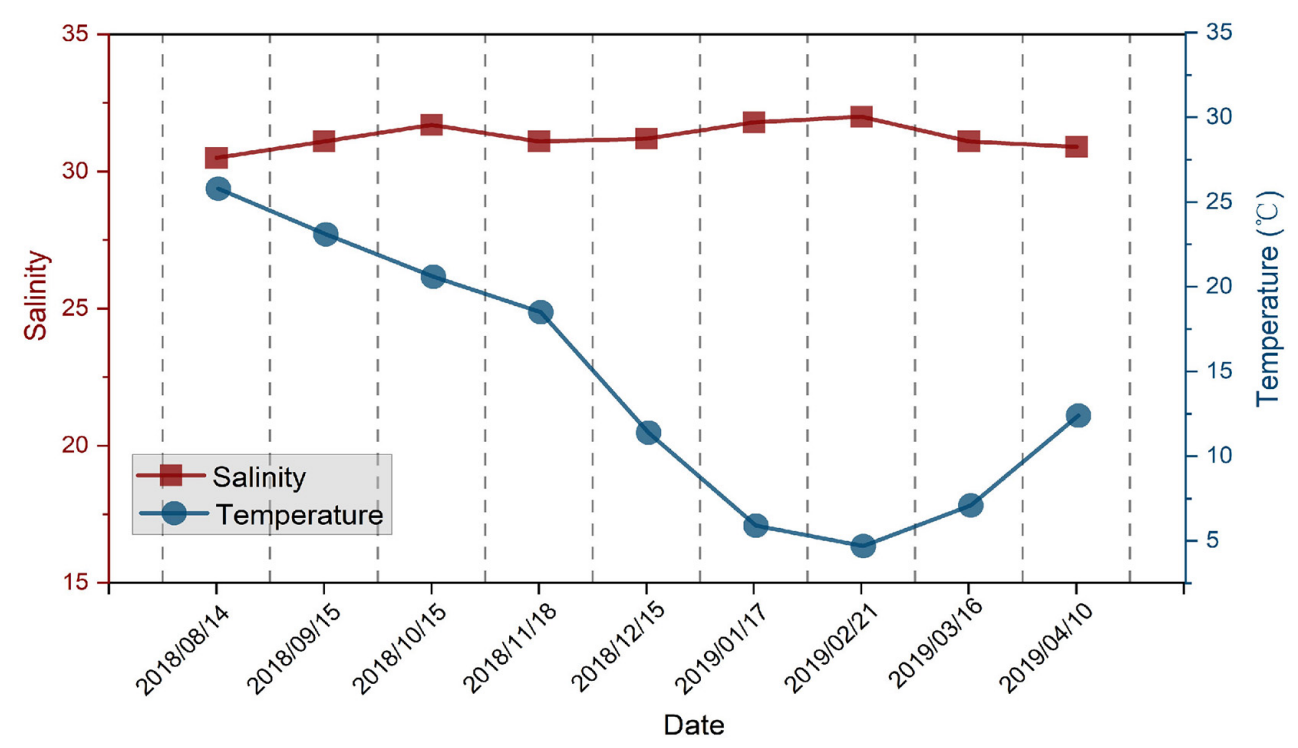

FIGURE 2 | Temperature and salinity at the Station in Jiaozhou Bay (Figure 1B) from August 2018 to April 2019.

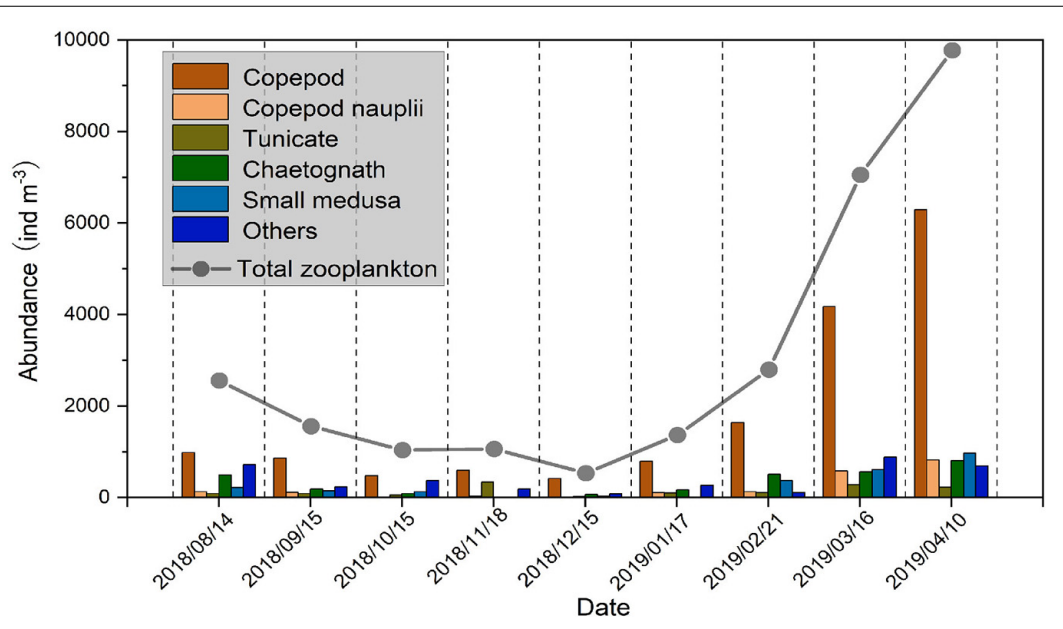

FIGURE 3 | Zooplankton abundance (ind $\mathrm{m}^{-3}$ ) collected by a II plankton net at the Station in Jiaozhou Bay from August 2018 to April 2019.

zooplankton abundance (ind $\mathrm{m}^{-3}$ ). We considered $P<0.05$ to be statistically significant.

\section{RESULTS}

\section{Temperature, Salinity, and Zooplankton Abundance}

During the study, the temperature at the sampling station ranged from 4.8 to $25.8^{\circ} \mathrm{C}$, while salinity ranged from 30 to 32 (Figure 2). Zooplankton collected by a II plankton net (160- $\mu \mathrm{m}$ mesh size) within the study area were comprised of $54.04 \pm 9.60 \%$ copepods (including copepods adults and copepodites), $4.82 \pm 3.34 \%$ copepod nauplii, $7.20 \pm 8.43 \%$ tunicates, $10.53 \pm 5.61 \%$ chaetognaths, $7.17 \pm 4.71 \%$ small medusae, and $16.23 \pm 9.18 \%$ others in abundance. Copepods formed the dominant zooplankton community in the present study area (Figure 3). Abundance of total zooplankton had significant seasonal variation, which decreased from August to December 2018 and then increased from January to April 2019, with an average abundance of $3157.11 \pm 3164.90$ ind $\mathrm{m}^{-3}$, and the highest value in this study was recorded in April 2019 (Figure 3).

\section{Gut Content and Prey Capture}

The mean size $( \pm \mathrm{SD})$ of $A$. coerulea polyps for gut content analysis in the 9-month study was $965.86 \pm 289.50 \mu \mathrm{m}$. There were no significant differences in polyp sizes between different months (one-way ANOVA: $F=0.264, P=0.976$ ) (Figure 4). A total of 50 polyps were sampled for gut content analysis each 


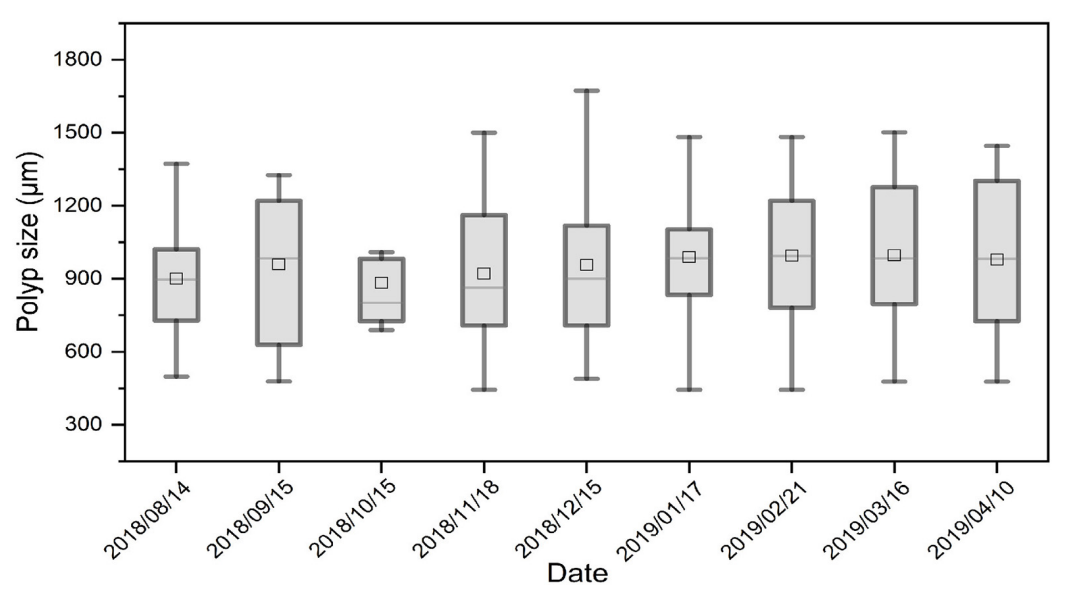

FIGURE 4 | Boxplot of the size diversities of $A$. coerulea polyps used for gut content analysis for each sampling date. One-way ANOVA analysis indicated that there were no significant differences in polyp sizes between different months ( $F=0.264, P=0.976$ ). The lower whisker, lower hinge, horizontal line, upper hinge, and upper whisker show minimum, lower quartile, median, upper quartile, and maximum size diversity, respectively. The squares in the boxplot indicated the mean values of polyp size.

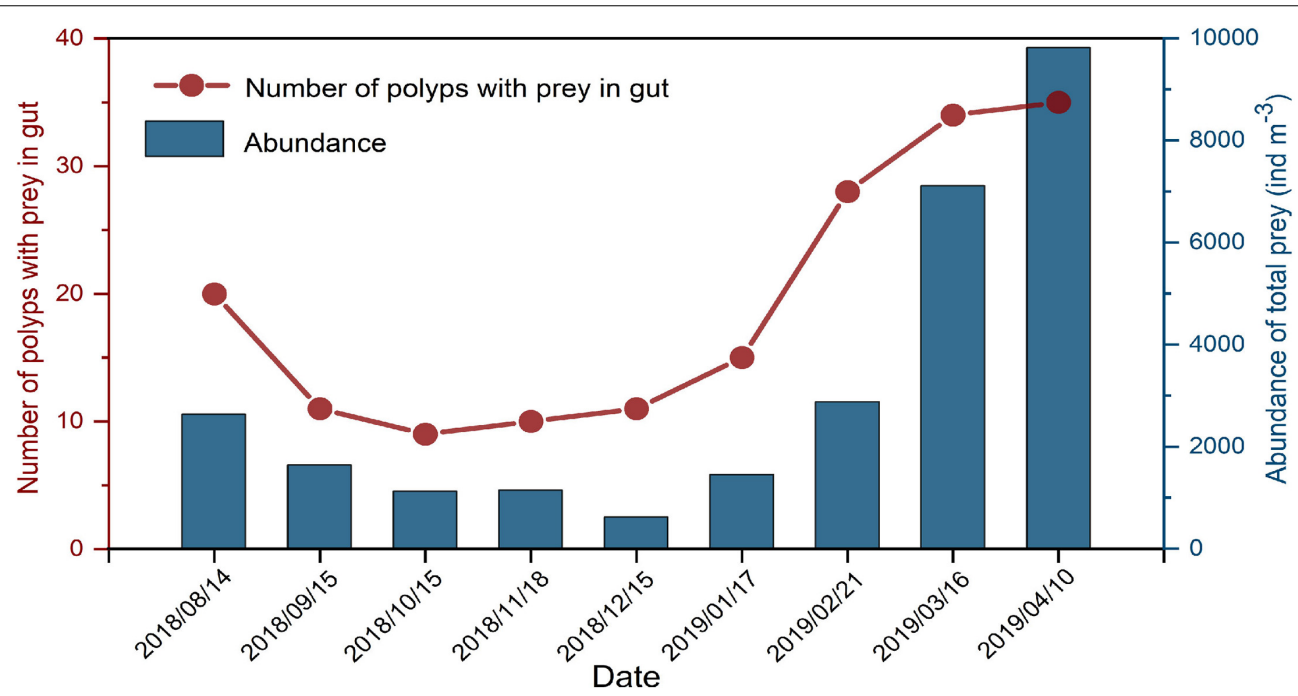

FIGURE 5 | The relationship between the number of polyps with prey in gut (50 polyps were collected on each sampling date) and abundance of zooplankton (ind $\mathrm{m}^{-3}$ ) during the study period. A Spearman correlation test showed that the number of polyps with prey in gut was significantly correlated with zooplankton abundance $\left(R^{2}=0.904, P=0.001, n=9\right)$.

month, and the number of polyps with prey in the gut varied in different months (Figure 5). The Spearman correlation test showed that the number of polyps with prey in the gut was significantly correlated with zooplankton abundance $\left(R^{2}=0.904\right.$, $P=0.001, n=9)$.

Copepods (copepod adults and copepodites), copepod nauplii, and ciliates (Tintinnids) were identified in the guts of polyps in Jiaozhou Bay during the study period. The gut content analysis indicated that copepods represented the bulk of the total prey intake in number $(88.02 \pm 10.58 \%)$, followed by copepod nauplii $(11.34 \pm 10.03 \%)$ and ciliates $(0.65 \pm 1.31 \%$; only three ciliates were found in three polyps' guts during February and March 2019) (Figure 6). However, numbers of prey in the gut of polyps had significant seasonal variations: the number of total prey (copepods, copepod nauplii, and ciliates together) in the gut of polyps on each sampling data (50 polyps) decreased from August 2018 to November 2018, and then increased from December 2018 to April 2019 (Figure 6).

The mean values of prey capture $\left(N\right.$, prey polyp $\left.{ }^{-1}\right)$ on copepods and copepod nauplii were $0.49 \pm 0.32$ and $0.10 \pm 0.11$ prey polyp $^{-1}$, respectively. The maximum values of $N$ both on copepods and copepod nauplii occurred in April 2019, with the maximum of 1.06 and 0.30 prey polyp ${ }^{-1}$, respectively (Figure 7). Prey capture was significantly affected by zooplankton abundance (Figure 7 and Table 2). 


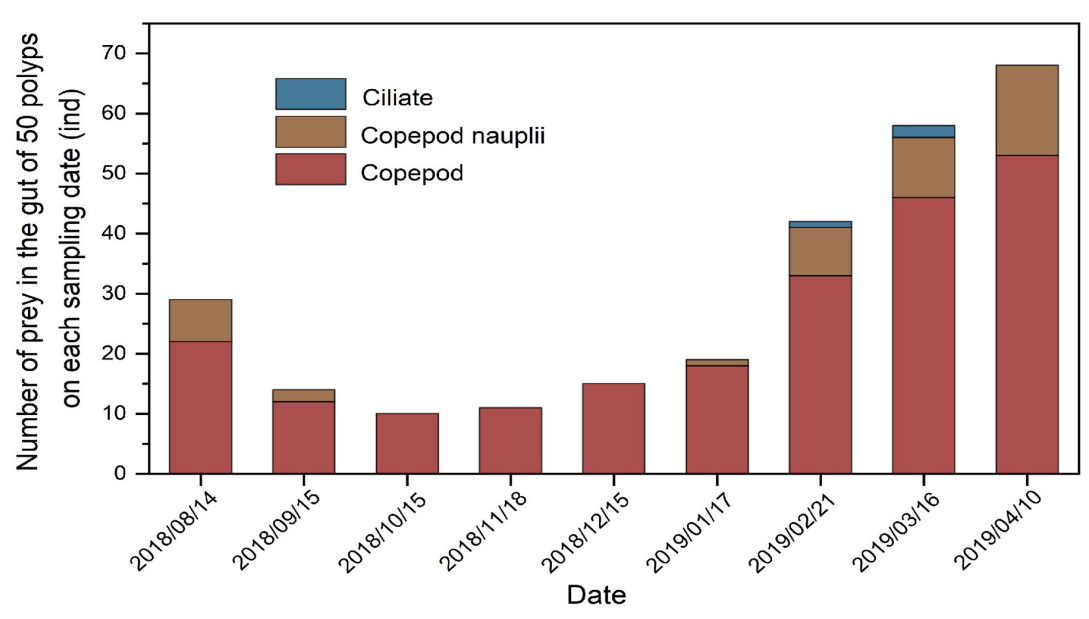

FIGURE 6 | Number of prey (copepods, copepod nauplii, and ciliates) in the gut of 50 polyps on each sampling date (50 polyps were detected on each sampling date). Sampling period ranged from August 2018 to April 2019.

\section{Digestion Rate}

The sizes of polyps sampled for the digestion experiments did not differ significantly among different months (one-way ANOVA: $F=0.588, P=0.785$ ), and were not significantly different from the polyps collected for gut content analysis (one-way ANOVA: $F=2.699, P=0.102$ ). Thus, the size of $A$. coerulea polyps was unlikely to be an influencing factor on the digestion experiment results, nor an influence in the use of these results for calculations of prey-capture rates.

Digestion processes indicated that an exponential decrease in the number of prey per polyp occurred over time in all digestion experiments (Figure 8); as temperature increased, both copepods (Figure 8A) and copepod nauplii (Figure 8B) in polyps' guts were digested more rapidly by A. coerulea polyp. Digestion of polyps was significantly affected by water temperature. The linear regressions for the digestions of copepods and copepod nauplii were as follows: $y=34.56-1.31 x[P<0.001$, $R^{2}=0.977 ; y=$ digestion time $(\mathrm{h}), x=$ temperature $\left.\left({ }^{\circ} \mathrm{C}\right)\right]$ and $y=12.78-0.45 x\left(P=0.001, R^{2}=0.931\right)$, respectively (Figure 9).

\section{Prey-Capture Rate and Ingestion Rate}

The prey-capture rate $\left(C\right.$, prey polyp $\left.\mathrm{p}^{-1} \mathrm{~d}^{-1}\right)$ in each month (Table 3) was calculated directly from the mean value of prey capture (prey polyp ${ }^{-1}$ ) and the digestion rate $(D, \mathrm{~h})$. Our results indicated that each $A$. coerulea polyp would consume, on average, $1.87 \pm 1.44$ copepods and $0.68 \pm 0.83$ copepod nauplii daily during the study period (Table 3 and Figure 10A). Values of $C$ varied in different months (Figure 10A), and the maximum $C$-value of 7.52 total prey (copepods and copepods nauplii together) polyp ${ }^{-1} \mathrm{~d}^{-1}$ happened in August 2018 (Figure 10A).

The carbon weight-specific ingestion rates of $A$. coerulea polyps ( $I_{w}, \mu \mathrm{g} \mathrm{C} \mu \mathrm{g} \mathrm{C}^{-1} \mathrm{~d}^{-1}$, copepods and copepods nauplii as prey) showed a large seasonal variation, which decreased from

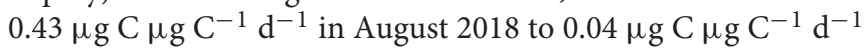
in December 2018, then increased to $0.17 \mu \mathrm{g} \mathrm{C} \mu \mathrm{g} \mathrm{C}^{-1} \mathrm{~d}^{-1}$ in April 2019 (Figure 10B). The mean $( \pm S D)$ value of $I_{w}$ was

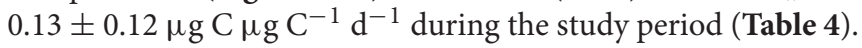

\section{DISCUSSION}

\section{Prey Capture of $A$. coerulea Polyps}

We cultured $A$. coerulea polyps in situ (Jiaozhou Bay) during August 2018 to April 2019 and evaluated their diet by analyzing gut contents; the results indicated that copepods, copepod nauplii, and ciliates were all captured by $A$. coerulea polyps. Compared to copepod nauplii and ciliates, copepods were frequent in polyps' guts comprising $88.02 \pm 10.58 \%$ in number of the total prey in this study. Consistent with our study result, a previous study by Östman (1997) indicated that the main prey for scyphopolyps (Aurelia and Cyanea) from the Gullmar Fjord on the Swedish west coast appeared to be small copepods, which occurred abundantly in water.

Previous studies have reported that the main food of the medusa stage of Aurelia is meso-zooplankton (Arai, 1997); for example, studies by Ishii and Tanaka (2001) and Uye and Shimauchi (2005) both found that copepods, which often dominate zooplankton biomass in eutrophic embayments, were an important food source for $A$. aurita medusae. The medusa can swim, concentrate prey around their oral parts, and excrete mucus to retain food items around their oral opening (Southward, 1955); polyps cannot actively move toward prey, and cannot accumulate prey particles by themselves (Kamiyama, 2011). The most important method of polyp predation is using their tentacles as a trap and capturing their prey with the help of nematocysts located on the tentacles (Kamiyama, 2011). For scyphopolyps, as a benthic suspension-feeding predator, the success of tentacle entrapment feeding is mainly based on the prey encounter rate (Kamiyama, 2011; Ikeda et al., 2017), implying that prey capture appeared to be determined by zooplankton availability. This was demonstrated by our study: the prey capture of $A$. coerulea polyp was highly dependent 


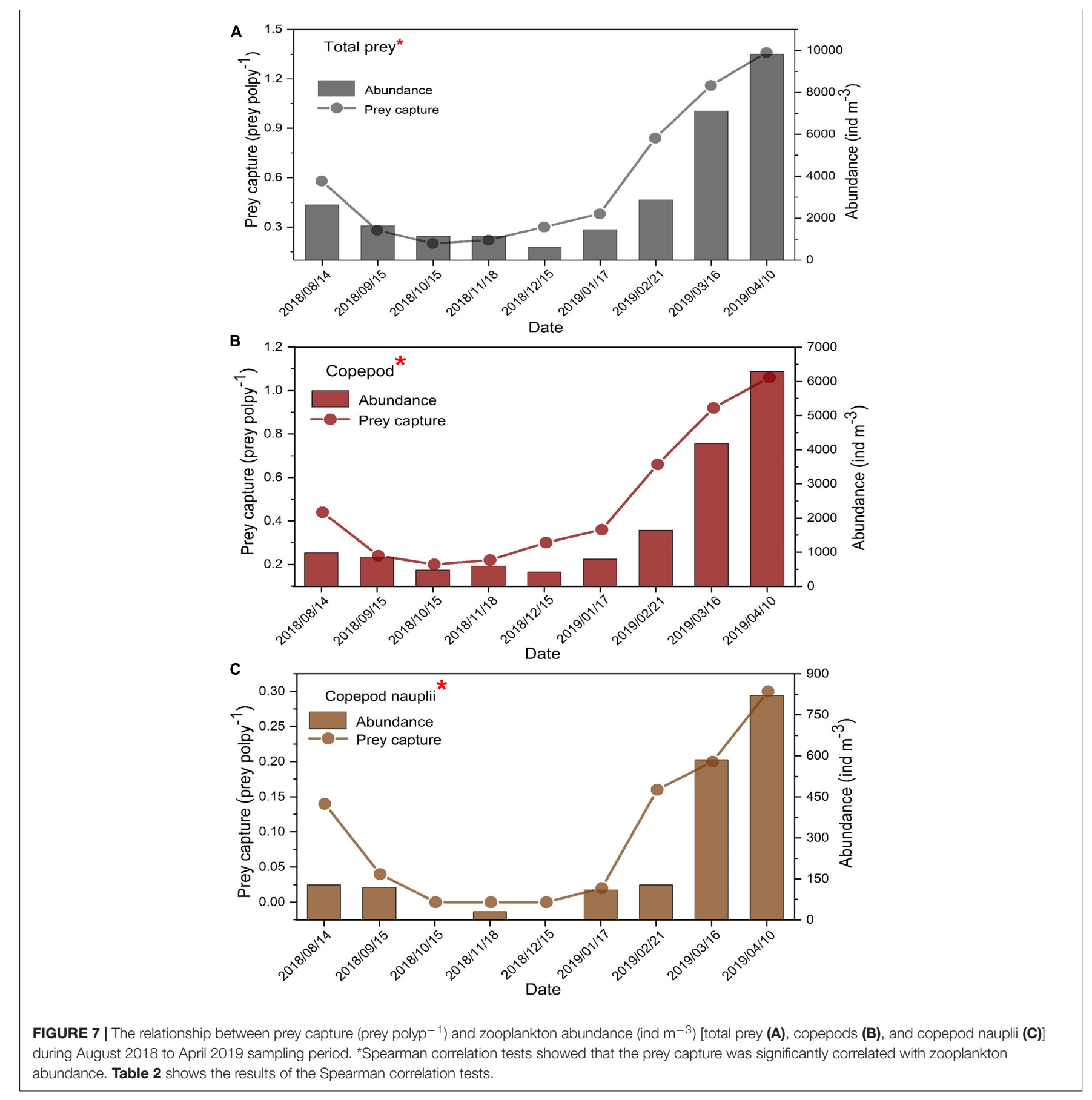

upon the abundance and frequency of planktonic prey in the polyp habitat (Figure 7 and Table 2). A similar correlation was observed between zooplankton abundance in the surrounding environment and the number of polyps containing prey items, which indicated that an increased higher zooplankton abundance was reflected by an increase in the number of polyps containing prey (Figure 5). This relationship also was reported by Coma et al. (1994) with the study of the prey capture of gorgonian Paramuricea clavata. Thus, the relatively high abundance of copepods in surrounding water (54.04 $\pm 9.60 \%$; Figure 3) might increase prey availability and the opportunity to encounter A. coerulea polyps. However, Ikeda et al. (2017) speculated that the most appropriate prey for polyps might be large copepod nauplii. Copepod nauplii only comprised a small part of the polyp diet in this study (Figure 6). Perhaps the relatively low prey capture of copepod nauplii was due to the low population abundance in our study area (4.82 $\pm 3.34 \%$; Figure 3). For benthic suspension-feeding predators, a previous study has indicated that their prey capture may be influenced by hydrodynamic processes (Tsounis et al., 2006). The plastic 
TABLE 2 | The results of Spearman correlation test for the relationship between zooplankton abundance and prey capture (prey polyp ${ }^{-1}$ ).

\begin{tabular}{|c|c|c|c|}
\hline \multirow{2}{*}{$\begin{array}{l}\text { Prey capture (prey } \\
\text { polyp }^{-1} \text { ) }\end{array}$} & \multicolumn{3}{|c|}{ Abundance (ind $\mathrm{m}^{-3}$ ) } \\
\hline & Total prey & Copepods & $\begin{array}{l}\text { Copepod } \\
\text { nauplii }\end{array}$ \\
\hline Total prey & $\begin{array}{l}R^{2}=0.867 \\
\boldsymbol{P}=0.002^{*}\end{array}$ & & \\
\hline Copepods & & $\begin{array}{l}R^{2}=0.867 \\
\boldsymbol{P}=0.002^{\star}\end{array}$ & \\
\hline Copepod nauplii & & & $\begin{array}{l}R^{2}=0.983 \\
\boldsymbol{P}<0.001^{\star}\end{array}$ \\
\hline
\end{tabular}

${ }^{\star} P$-values given in bold are significant at $5 \%$ level.

plates carrying polyps were fixed on rooves (simulation of a vessel bottom) in situ; the rooves, with four open sides, were horizontally moored with the polyps' attachment side facing downward (Figure 1C), mimicking the natural state in Jiaozhou Bay (Feng et al., 2017). Therefore, normal water-flow may not be disturbed.

Micro-zooplankton are also numerically important components of seawater zooplankton communities (Pierce and Turner, 1992). Kamiyama (2011) showed that planktonic ciliates, a main component of micro-zooplankton, served as food items for A. aurita polyps under laboratory conditions. However, in the present study, ciliates were found in the guts of A. coerulea polyps rarely (Figure 6). Östman (1997) also rarely found ciliates in the guts of polyps. This may because ciliates are fragile and readily destroyed by mechanical stress during polyp feeding (Östman, 1997; Kamiyama, 2011); the rapid digestion of ciliates may also cause a short retention time of ciliates in the gut of polyps. These factors may cause an underestimate of the contribution of ciliates to the diets of A. coerulea polyps in this study. According to one previous study, the abundance of ciliates has a great seasonal variation in our study area with the value of 300-2418 ind $\mathrm{L}^{-1}$ (Yu et al., 2011). However, previous studies have indicated that faster prey may encounter $A$. aurita polyps more frequently (Kamiyama, 2011; Ikeda et al., 2017), which was corroborated by the theoretical encounter model (Greene et al., 1986; Rothschild and Osborn, 1988). Therefore, the relatively low swimming speed of ciliates probably reduced the opportunity to encounter to scyphopolyps compared to mesozooplankton (Kamiyama, 2011). In addition, compared to larger prey, like copepods, ciliates only provide a small energy source from one prey.

In summary, copepods that were characterized by larger prey availability, faster swimming speed, and higher carbon weight might account for the majority of the diet of $A$. coerulea polyps in Jiaozhou Bay.

\section{Ingestion Rate of $A$. coerulea Polyp}

The carbon weight-specific ingestion rates of $A$. coerulea polyp estimated in this study were based on the prey capture of copepods and copepod nauplii, but not contained ciliates due to the lack of specific digestion time. Therefore, it is important to

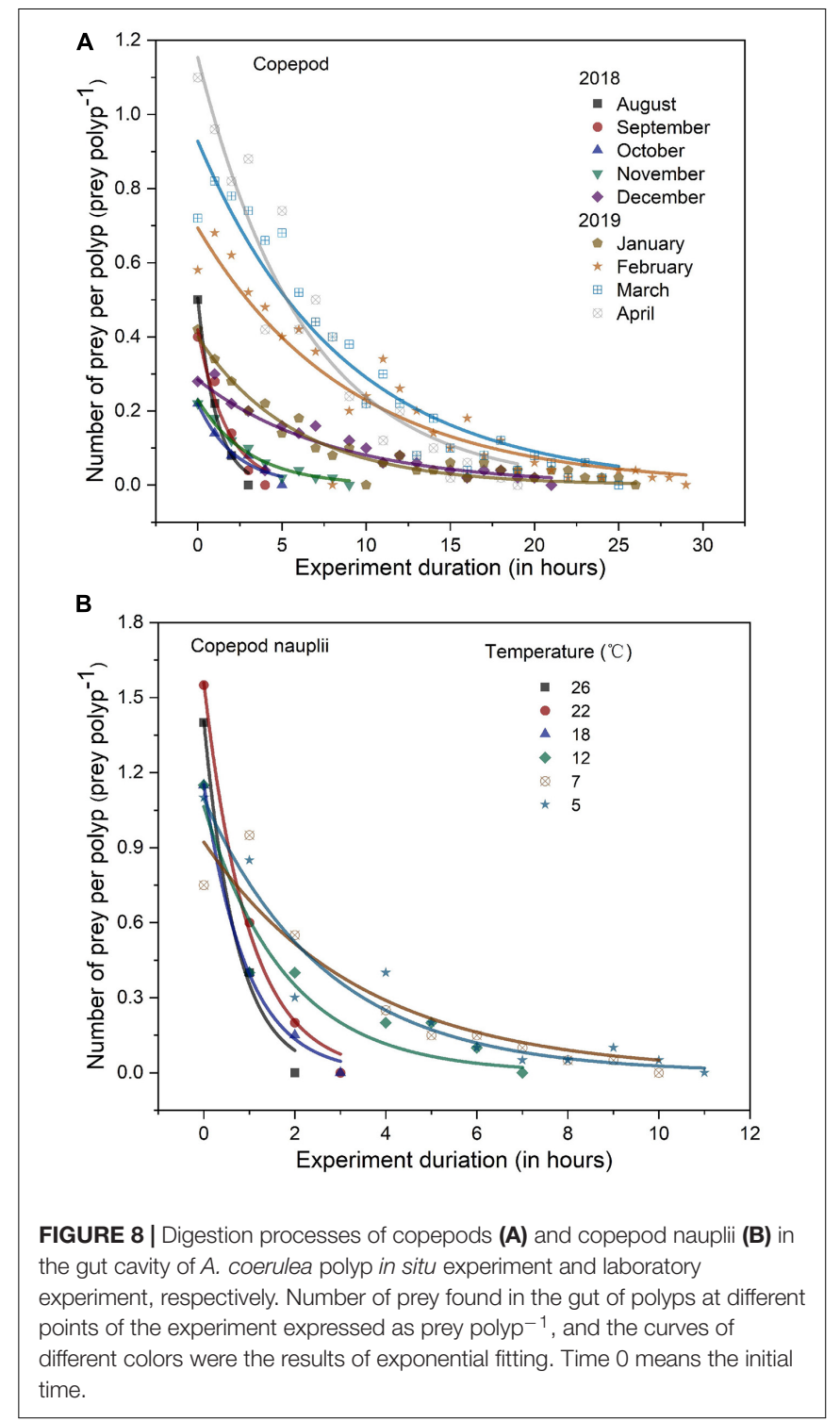

acknowledge that the ingestion rate of $A$. coerulea polyp likely be even larger than presented in this study (ranging from 0.04 to $\left.0.43 \mu \mathrm{g} \mathrm{C} \mu \mathrm{g} \mathrm{C}^{-1} \mathrm{~d}^{-1}\right)$. However, few ciliates were found in the polyps' guts in this study, whereas copepods represented the bulk of the total prey intake in number (88.02 $\pm 10.58 \%)$, followed by copepod nauplii $(11.34 \pm 10.03 \%)$ as indicated by the results of gut content analysis (Figure 6). Digestion rates of copepod nauplii could not be measured directly in situ, but were determined in laboratory conditions. The nauplii of $P$. annandalei (Calanoida) that was not a common species in Jiaozhou Bay were used as prey to determine the digestion time of copepod nauplii. The mean carapace length of these copepod nauplii was $204.7 \mu \mathrm{m}$, which was similar to the carapace length of copepod nauplii (237.96 $\pm 45.13 \mu \mathrm{m})$ detected in polyp guts. Thus, it is reasonable to use the results of the digestion of $P$. annandalei nauplii in the calculations of ingestion rate. 


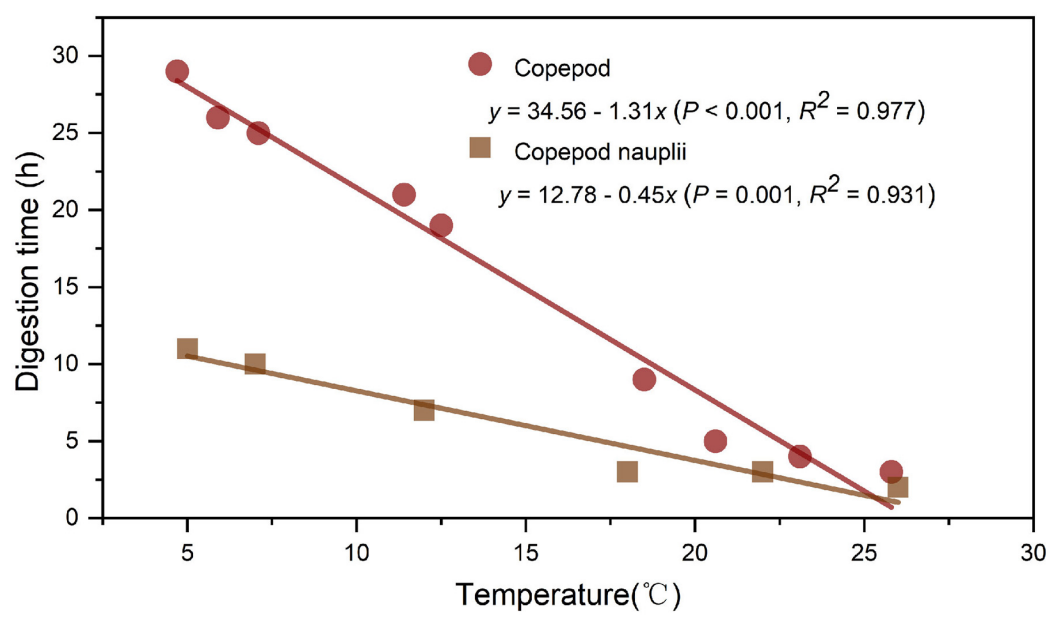

FIGURE 9 | The relationship between temperature and digestion time of copepods and copepod nauplii.

We compared the carbon weight-specific ingestion rates of Aurelia polyps $\left(I_{w}, \mu \mathrm{g} \mathrm{C} \mu \mathrm{g} \mathrm{C}^{-1} \mathrm{~d}^{-1}\right)$ estimated in laboratory experiments by previous studies (Kamiyama, 2011; Ikeda et al., 2017). Kamiyama (2011) conducted feeding experiments using ciliates (Favella ehrenbergii, Strombidium sp., and Myrionecta rubra) as prey at $20^{\circ} \mathrm{C}$, and indicated that ingestion rates of $A$. aurita polyps on all ciliates increased with increasing ciliate density up to ca. 300-500 $\mu \mathrm{g} \mathrm{C} \mathrm{L}^{-1}$. $I_{w}$ value of $A$. aurita polyp

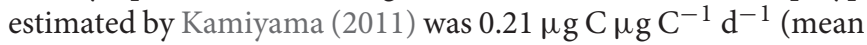
carbon content $38.1 \mu \mathrm{g}$ of polyp). This estimated value of $I_{w}$ was about twice as large as the $I_{w}$ (copepods and copepod nauplii as prey) that we estimated at the same temperature $(0.07-0.12 \mu \mathrm{g}$ $\mathrm{C} \mu \mathrm{g} \mathrm{C}^{-1} \mathrm{~d}^{-1}$, temperature of $\left.18.5-20.6^{\circ} \mathrm{C}\right)$. However, the high ciliates densities in Kamiyama's experiments are unrealistic in Jiaozhou Bay, as the annual average biomass of ciliate generally

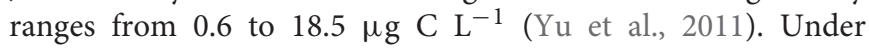
controlled laboratory conditions, Ikeda et al. (2017) constructed an empirical energy budget model for natural A. aurita polyp population. Based on the bioenergetic model (Ikeda et al., 2017): $I_{W}=13 \times(0.026 T-0.11) \times P_{c}\left[T:\right.$ water temperature $\left({ }^{\circ} \mathrm{C}\right) ; P_{c}$ : prey carbon density $\left.\left(\mu \mathrm{g} \mathrm{C} \mathrm{mL}^{-1}\right)\right]$, we estimated the $I_{w}$ of A. coerulea polyp of ciliates as prey $\left(T=20.6^{\circ} \mathrm{C}\right.$ in October) using a ciliate biomass density of about $0.0011 \mu \mathrm{g} \mathrm{C} \mathrm{mL}-1$ $\left(P_{c}\right)$ near our study station in Jiaozhou Bay (Yu et al., 2011). The evaluated $I_{w}$ of ciliates (as prey) was about $0.006 \mu \mathrm{g} \mathrm{C} \mu \mathrm{g}$ $\mathrm{C}^{-1} \mathrm{~d}^{-1}$, which was far less than the $I_{w}$ value estimated based on gut content in this study $\left(0.12 \mu \mathrm{g} \mathrm{C} \mu \mathrm{g} \mathrm{C}^{-1} \mathrm{~d}^{-1}\right.$ in October). According to the study of Ikeda et al. (2017), the respiration rate $\left(R, \mathrm{ng} \mathrm{O}_{2} \mu \mathrm{g} \mathrm{C}^{-1} \mathrm{~d}^{-1}\right)$ of polyps was significantly affected by temperature, and the metabolic rate $\left(M, \mu \mathrm{gC} \mu \mathrm{g} \mathrm{C}^{-1} \mathrm{~d}^{-1}\right)$ could be expressed as $M=0.0055 e^{0.066 T}$. Therefore, the estimated metabolic rate of $A$. coerulea polyp at $20.6^{\circ} \mathrm{C}$ was approximately $0.021 \mu \mathrm{g} \mathrm{C} \mu \mathrm{g} \mathrm{C}^{-1} \mathrm{~d}^{-1}$, which was more than three times larger than the estimated $I_{w}$ of $A$. coerulea polyp of ciliates as prey. This also suggested that ciliates are not the main food source for A. coerulea polyp, but a supplement of polyp diet in Jiaozhou Bay.
Aurelia coerulea polyps had a large seasonal variation in $I_{w}$, ranging from 0.04 to $0.43 \mu \mathrm{g} \mathrm{C} \mu \mathrm{g} \mathrm{C}^{-1} \mathrm{~d}^{-1}$ within the study period, which was also indicated by the estimation of Ikeda et al. (2017). This was due to the temperature variations (effect on digestion) and the variations in prey availability in different months. The relatively high values of $I_{w}$ for A. coerulea polyp were found in August 2018 and April 2019, with the values of 0.43 and $0.17 \mu \mathrm{g} \mathrm{C} \mu \mathrm{g} \mathrm{C}^{-1} \mathrm{~d}^{-1}$, respectively (Figure 10B). The digestion time of copepods was $3 \mathrm{~h}$ measured in August 2018 (temperature $=25.8^{\circ} \mathrm{C}$ ), and of copepod nauplii was $2 \mathrm{~h}$ measured at $26^{\circ} \mathrm{C}$ for A. coerulea polyp. The rapid digestion of prey might result in the highest $I_{w}$ of $A$. coerulea polyp in August 2018. In addition, the relatively higher $I_{w}$ measured in April 2019 might be due to the large zooplankton abundance, which increased prey availability for A. coerulea polyp. Thus, more rapid digestion of prey at higher temperature conditions and greater prey availability would cause higher ingestion rates in polyps.

The ingested carbon of $A$. coerulea polyp population might have different utilization patterns in different seasons because of the seasonal variation in eco-physiology or life cycle characteristics of Aurelia polyps in temperate offshore waters (Han and Uye, 2010; Thein et al., 2012), including Jiaozhou Bay (Wang N. et al., 2015; Feng et al., 2018). During the warm season (temperature $>15^{\circ} \mathrm{C}$, from August to November), the estimated $I_{w}$ values were $0.07-0.43 \mu \mathrm{g} \mathrm{C} \mu \mathrm{g} \mathrm{C}^{-1} \mathrm{~d}^{-1}$ (Table 4). The estimated metabolic rates were $0.019-0.03 \mu \mathrm{g} \mathrm{C} \mu \mathrm{g} \mathrm{C}^{-1} \mathrm{~d}^{-1}$ during this period (according to $M=0.0055 e^{0.066 T}$; Ikeda et al., 2017). Hence, the mean growth rate of $A$. coerulea polyp during August and November in Jiaozhou Bay was estimated to be $0.124 \pm 0.123 \mu \mathrm{g} \mathrm{C} \mu \mathrm{g} \mathrm{C}^{-1} \mathrm{~d}^{-1}$ (assimilation efficiency assumed to be 0.8 ; Schneider, 1989). In this period, owing to the relatively large growth rate, the ingested carbon might be mainly used for somatic growth and population expansion through the budding pattern for A. coerulea polyp population in Jiaozhou Bay. This was also demonstrated by Feng et al. (2017). During the cold season (temperature $<15^{\circ} \mathrm{C}$, from December 2018 to April 2019), the estimated growth rate was $0.057 \pm 0.042 \mu \mathrm{g} \mathrm{C} \mu \mathrm{g}$ 
$\mathrm{C}^{-1} \mathrm{~d}^{-1}$. Reproduction by budding and podocysts of $A$. coerulea polyps may greatly diminish during this period due to cold water temperature (Han and Uye, 2010; Feng et al., 2018). However, seasonal cooling may stimulate some physiological changes of A. coerulea polyps in preparation for metamorphosis into strobilae (Feng et al., 2018). Thus, the majority of carbon intake of polyps during this period may be incorporated into somatic growth in preparation for strobilation.

\section{Potential Effects of Polyp Predation on Pelagic Ecosystem}

In shallow water, benthic cnidarian feeders can affect pelagic plankton communities by significantly reducing plankton abundance (e.g., Coma et al., 1995, 1999; Gili and Coma, 1998; Tsounis et al., 2006). Much evidence has suggested that benthic cnidarians, including the Octocorallia (Coma et al., 1994; Ribes et al., 1999; Rossi et al., 2004), Eudendrium (Barange and Gili, 1988), and Obelia (Orejas et al., 2013), are important components of the benthic-pelagic-coupling processes of littoral marine ecosystems. A previous study has indicated that Aurelia polyps covered large areas of hardbottom substrates between 1 and $20 \mathrm{~m}$ deep (Gröndahl, 1988b). A. aurita planulae may settle gregariously: polyp densities of $60,000-400,000$ polyps $\mathrm{m}^{-2}$ have been reported on the west coast of Sweden (Gröndahl, 1988a,b); Purcell et al. (2009) found that Aurelia labiata polyps covered $58.3 \pm 0.6 \%$ of the available surface area beneath marina floats in Cornet Bay, WA, United States, and the mean polyp density was 9.3 polyps $\mathrm{cm}^{-2}$. Abundant scyphopolyps, with a predation strategy similar to other benthic suspension-feeding predators (Barange and Gili, 1988), may also play an important role in energy and matter exchange between the plankton and the benthos in littoral ecosystems, as Marcus and Boero (1998) emphasized that benthic-pelagic couplings determined the productivity and biological structures of coastal aquatic ecosystems. However, this energy and matter exchange has been ignored, perhaps because the polyp stage causes a lesser degree of ecosystem damage than does the medusa stage.

Han and Uye (2010) estimated that $4 \mu \mathrm{g} \mathrm{C}$ polyp ${ }^{-1} \mathrm{~d}^{-1}$ was the maximum ingestion rate of natural polyps on a diet of the copepod Oithona davisae. If the density of A. aurita polyps on the Swedish coast as estimated by Gröndahl (1988b) was used to approximate the effects of scyphopolyps predation on pelagic prey items, we found that the overall impact of the scyphopolyp population was between 240 and $1600 \mathrm{mg} \mathrm{C}$ polyps $\mathrm{m}^{-2} \mathrm{~d}^{-1}$. This estimate is an initial approximation, because polyp densities and spatial and temporal variations in prey-capture rates differed. In view of the high spatial and temporal variability in prey-capture rates, grazing impact probably differs among populations in different environments. However, this suggests that scyphopolyps may play a significant role in planktonbenthos coupling. According to underwater surveys performed by our divers, the maximum density of $A$. coerulea polyps was approximately 3-6 polyps $\mathrm{cm}^{-2}$ on the bottom of marina floats and along the concrete walls of port installations in Jiaozhou Bay (unpublished data). The maximum grazing impact of the 


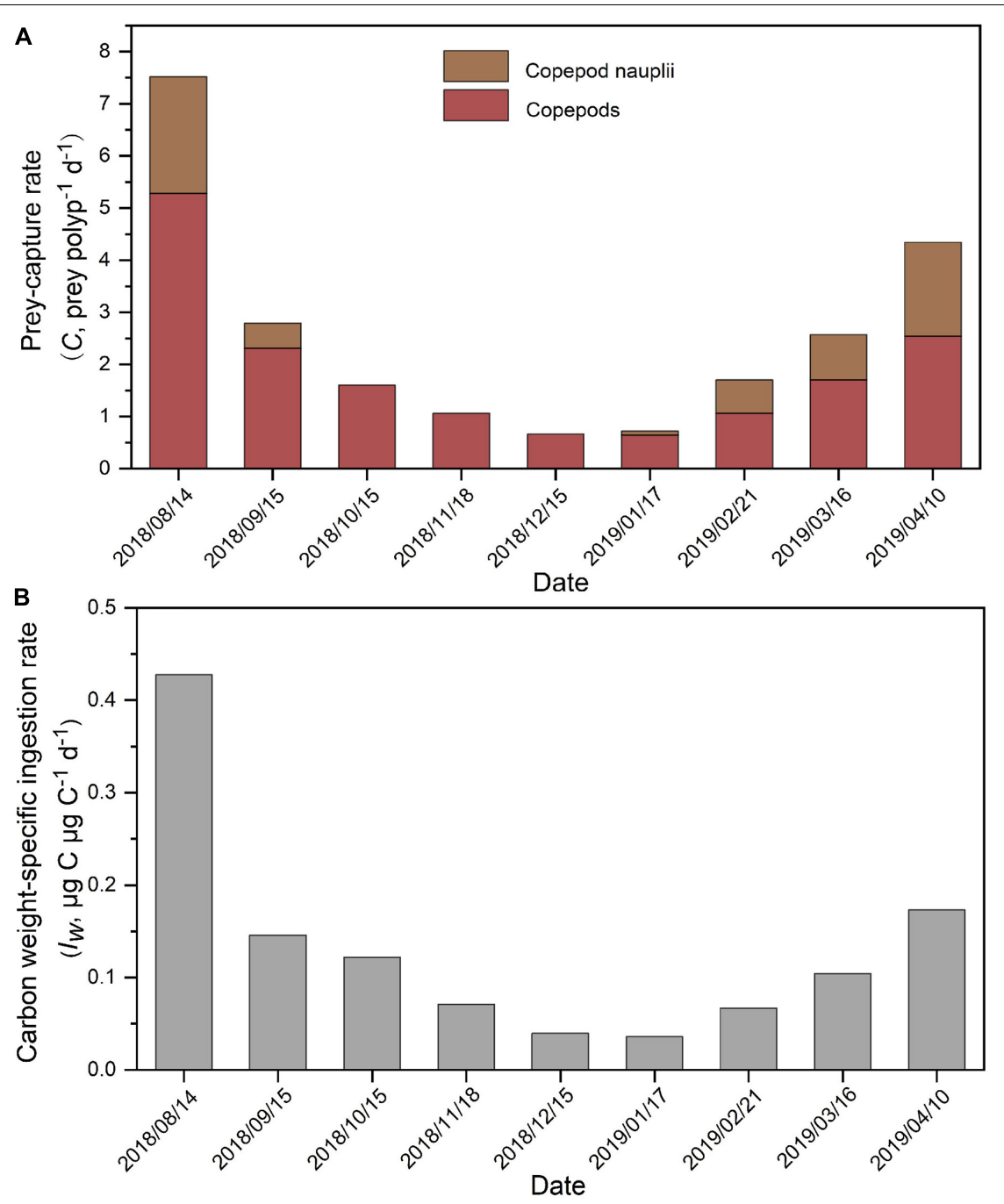

FIGURE 10 | Prey-capture rate (C, prey polyp $\left.{ }^{-1} \mathrm{~d}^{-1}\right)$ of copepods and copepod nauplii (A) and seasonal variation in carbon weight-specific ingestion rates for A. coerulea polyps (Iw, $\mu \mathrm{g} \mathrm{C} \mu \mathrm{g} \mathrm{C}^{-1} \mathrm{~d}^{-1}$; (B)) during August 2018 to April 2019.

TABLE 4 | Ingestion rates (I, $\mu \mathrm{g} C$ polyp ${ }^{-1} \mathrm{~d}^{-1}$ ) and carbon weight-specific ingestion rates (Iw, $\mu \mathrm{g} \mathrm{C} \mu \mathrm{g} \mathrm{C}^{-1} \mathrm{~d}^{-1}$ ) of $A$. coerulea polyps from August 2018 to April 2019.

\begin{tabular}{|c|c|c|c|c|c|c|c|c|c|c|}
\hline Sampling date & 14 August & 15 September & 15 October & 18 November & 15 December & 17 January & 21 February & 16 March & 10 April & Mean $( \pm S D)$ \\
\hline$I\left(\mu \mathrm{g} C\right.$ polyp $\left.{ }^{-1} \mathrm{~d}^{-1}\right)$ & 4.48 & 1.84 & 1.20 & 0.80 & 0.50 & 0.50 & 0.94 & 1.48 & 2.33 & $1.56 \pm 1.25$ \\
\hline
\end{tabular}

$W(\mu g C)$ is the mean carbon weight of polyps on each sampling date.

A. coerulea polyp population in Jiaozhou Bay ranged from 44 to $88 \mathrm{mg} \mathrm{C}$ polyps $\mathrm{m}^{-2} \mathrm{~d}^{-1}$ (mean ingestion rate: $1.46 \mu \mathrm{g}$ C polyp ${ }^{-1} \mathrm{~d}^{-1}$ ). This abundant accumulation of polyps might create high feeding pressure on the pelagic ecosystem in Jiaozhou Bay. Marine waste (e.g., plastics, glass, and wood), mariculture rafts, and waterfront construction projects provide additional areas suitable for polyp attachment, facilitating habitat expansion, and supporting polyp population growth (Uye and Ueta, 2004; Holst and Jarms, 2007). Scyphomedusae polyp blooms might influence the pelagic ecosystem because polyps play an important predatory role in the plankton-benthos energy transfer process of littoral ecosystems.

\section{CONCLUSION}

Gut content analysis indicated that copepods, copepod nauplii, and ciliates could be captured by A. coerulea polyps. Copepods are an important source of nutrition for the polyp stage of A. coerulea population in Jiaozhou Bay. Prey capture of 
A. coerulea polyp (prey polyp ${ }^{-1}$ ) varied among months, and was positively influenced by abundance of planktonic prey in the surrounding water. Our results indicated seasonal variations in ingestion rates of $A$. coerulea polyp in Jiaozhou Bay, and the relatively high values of ingestion rates occurred in August 2018 and April 2019 with more rapid digestion of prey and greater prey availability. Massive scyphomedusae polyp blooms may contribute to the energy flow of littoral ecosystems.

\section{DATA AVAILABILITY STATEMENT}

The original contributions presented in the study are included in the article/supplementary material, further inquiries can be directed to the corresponding authors.

\section{ETHICS STATEMENT}

This study was carried out in accordance with the current laws in China. There are no legal or ethical restrictions involving jellyfish and zooplankton populations.

\section{AUTHOR CONTRIBUTIONS}

WP, ZF, and SS contributed to conception and design of the study. WP and ZF led the writing of this study. WP and GD executed

\section{REFERENCES}

Arai, M. N. (1997). A Functional Biology of Scyphozoa. London: Chapman and Hall. Barange, M., and Gili, J. M. (1988). Feeding cycles and prey capture in Eudendrium racemosum (Cavolini, 1785). J. Exp. Mar. Biol. Ecol. 115, 281-293. doi: 10.1016/ 0022-0981(88)90160-8

Berggreen, U., Hansen, B., and Kiørboe, T. (1988). Food size spectra, ingestion and growth of the copepod Acartia tonsa during development: implications for determination of copepod production. Mar. Biol. 99, 341-352. doi: 10.1007/ bf02112126

Coma, R., Gili, J. M., and Zabala, M. (1995). Trophic ecology of a benthic marine hydroid, Campanularia everta. Mar. Ecol. Prog. Ser. 119, 211-220. doi: 10.3354/ meps119211

Coma, R., Gili, J. M., Zabala, M., and Riera, T. (1994). Feeding and prey capture cycles in the aposymbiontic gorgonian Paramuricea clavata. Mar. Ecol. Prog. Ser. 115, 257-270. doi: 10.3354/meps115257

Coma, R., Ribes, M., Orejas, C., and Gili, J. M. (1999). Prey capture by a benthic coral reef hydrozoan. Coral Reefs 18, 141-145. doi: 10.1007/s003380050168

Condon, R., Duarte, C. M., Pitt, K. A., Robinson, K. L., Lucas, C. H., Sutherland, K. R., et al. (2013). Recurrent jellyfish blooms are a consequence of global oscillations. Proc. Natl. Acad. Sci. U.S.A. 110, 1000-1005.

Dong, Z. J., Liu, D., and Keesing, J. K. (2010). Jellyfish blooms in China: dominant species, causes and consequences. Mar. Pollut. Bull. 60, 954-963. doi: 10.1016/ j.marpolbul.2010.04.022

Duarte, C. M., Pitt, K. A., Lucas, C. H., Purcell, J. E., Uye, S., Robinson, K., et al. (2013). Is global ocean sprawl a cause of jellyfish bloom? Front. Ecol. Environ. 11:91-97. doi: 10.1890/110246

Feng, S., Wang, S. W., Sun, S., Zhang, F., Zhang, G. T., Liu, M. T., et al. (2018). Strobilation of three scyphozoans (Aurelia coelurea, Nemopilema nomurai, and Rhopilema esculentum) in the field at Jiaozhou Bay, China. Mar. Ecol. Prog. Ser. 591, 141-153. doi: $10.3354 /$ meps 12276 the sampling and samples analysis. WP organized the database and performed the statistical analysis. All authors contributed critically to the drafts and gave final approval for publication.

\section{FUNDING}

This work was financially supported by the National Key Research and Development Program of China (2017YFC1404405 and 2017YFC1404401), the Marine S\&T Fund of Shandong Province for Pilot National Laboratory for Marine Science and Technology (Qingdao) (No. 2018SDKJ0504-3), Strategic Priority Research Program of the Chinese Academy of Sciences (XDA19060201 and XDA19060203), and Mount Tai Scholar Climbing Plan to SS.

\section{ACKNOWLEDGMENTS}

We thank the captain and crew of the "Haiou" research vessel. We thank Wang Jun Jian and Xian Haochen for help with sampling in Jiaozhou Bay. We thank Feng Song for taking care of the polyps during the experiment. We also thank Wang Junjian, Cheng Fangping, Wang Chaofeng, and $\mathrm{He}$ Cheng for help in identification of gut contents. We are grateful to the reviewers and the editor for their valuable comments.

Feng, S., Wang, S. W., Zhang, G. T., Sun, S., and Zhang, F. (2017). Selective suppression of in situ proliferation of scyphozoan polyps by biofouling. Mar. Pollut. Bull. 114, 1046-1056. doi: 10.1016/j.marpolbul.2016.10.062

Gili, J. M., and Coma, R. (1998). Benthic suspension feeders: their paramount role in littoral marine food webs. Trends. Ecol. Evol. 13, 316-321. doi: 10.1016/ s0169-5347(98)01365-2

Greene, C. H., Landry, M. R., and Monger, B. C. (1986). Foraging behavior and prey selection by the ambush entangling predator Pleurobrachia bachei. Ecology 67, 1493-1501. doi: 10.2307/1939080

Gröndahl, F. (1988b). Interactions between polyps of Aurelia aurita and planktonic larvae of scyphozoans: an experimental study. Mar. Ecol. Prog. Ser. 45, 87-93. doi: 10.3354/meps045087

Gröndahl, F. (1988a). A comparative ecological study on the scyphozoans Aurelia aurita, Cyanea capillata and Cyanea lamarckii in the Gullmar Fjord, Western Sweden. Mar. Biol. 97, 541-550. doi: 10.1007/bf00391050

Han, C. H., and Uye, S. (2010). Combined effects of food supply and temperature on asexual reproduction and somatic growth of polyps of the common jellyfish Aurelia aurita (s.1.). Plankton Benthos Res. 5, 98-105. doi: 10.3800/pbr.5.98

Hansson, L. J., Moeslund, O., Kiørboe, T., and Riisgård, H. U. (2005). Clearance rates of jellyfish and their potential predation impact on zooplankton and fish larvae in a neritic ecosystem (limfjorden, denmark). Mar. Ecol. Prog. Ser. 304, 117-131. doi: 10.3354/meps304117

Holst, S., and Jarms, G. (2007). Substrate choice and settlement preferences of planula larvae of five Scyphozoa (Cnidaria) from German Bight, North Sea. Mar. Biol. 151, 863-871. doi: 10.1007/s00227-006-0530-y

Huang, X., Huang, B., Zeng, Y., and Li, S. (2015). Effect of dinoflagellates and diatoms on the feeding response and survival of Aurelia sp. polyps. Hydrobiologia 754, 179-188. doi: 10.1007/s10750-014-2023-1

Ikeda, H., Mizota, C., and Uye, S. (2017). Bioenergetic characterization in Aurelia aurita (Cnidaria: Scyphozoa) polyps and application to natural polyp populations. Mar. Ecol. Prog. Ser. 568, 87-100. doi: 10.3354/meps 12055 
Ishii, H., and Katsukoshi, K. (2010). Seasonal and vertical distribution of Aurelia aurita polyps on a pylon in the innermost part of Tokyo Bay. J. Oceanogr. 66, 329-336. doi: 10.1007/s10872-010-0029-5

Ishii, H., and Tanaka, F. (2001). Food and feeding of Aurelia aurita in Tokyo Bay with an analysis of stomach contents and a measurement of digestion times. Hydrobiologia 451, 311-320. doi: 10.1007/978-94-010-0722-1_26

Kamiyama, T. (2011). Planktonic ciliates as a food source for the scyphozoan Aurelia aurita (s.l.): feeding activity and assimilation of the polyp stage. J. Exp. Mar. Biol. Ecol. 407, 207-215. doi: 10.1016/j.jembe.2011.06.016

Lucas, C. H. (2001). Reproduction and life history strategies of the common jellyfish, Aurelia aurita, in relation to its ambient environment. Hydrobiologia 451, 229-246. doi: 10.1007/978-94-010-0722-1_19

Lucas, C. H., Graham, W. M., and Widmer, C. (2012). Jellyfish life histories: role of polyps in forming and maintaining scyphomedusa populations. Adv. Mar. Biol. 63, 133-184. doi: 10.1016/b978-0-12-394282-1.00003-x

Lucas, C. H., and Williams, J. A. (1994). Population dynamics of the scyphomedusa Aurelia aurita in Southampton Water. J. Plankton. Res. 16, 879-895. doi: 10.1093/plankt/16.7.879

Marcus, N. H., and Boero, F. (1998). Production and plankton community dynamics in coastal aquatic systems: the importance of benthic-pelagic coupling and the forgotten role of life cycles. Limnol. Oceanogr. 43, 763-768. doi: 10.4319/lo.1998.43.5.0763

Martinussen, M. B., and Båmstedt, U. (1999). Nutritional ecology of gelatinous planktonic predators. Digestion rate in relation to type and amount of prey. J. Exp. Mar. Biol. Ecol. 232, 61-84. doi: 10.1016/s0022-0981(98)00101-4

Mills, C. E. (2001). Jellyfish blooms: are populations increasing globally in response to changing ocean conditions? Hydrobiologia 451, 55-68. doi: 10.1007/978-94010-0722-1_6

Miyake, H., Terazaki, M., and Kakinuma, Y. (2002). On the polyps of the common jellyfish Aurelia aurita in Kagoshima Bay. J. Oceanogr. 58, 451-459.

Möller, H. (1980). Population dynamics of Aurelia aurita medusae in Kiel Bight, Germany (FRG). Mar. Biol. 60, 123-128. doi: 10.1007/bf00 389155

Olesen, N. J., Frandsen, K., and Riisgard, H. U. (1994). Population dynamics, growth and energetics of jellyfish Aurelia aurita in a shallow fjord. Mar. Ecol. Prog. Ser. 105, 9-18. doi: 10.3354/meps105009

Omori, M., Ishii, H., and Fujinaga, A. (1995). Life history strategy of Aurelia aurita (Cnidaria, Scyphomedusae) and its impact on the zooplankton community of Tokyo Bay. ICES J. Mar. Sci. 52, 597-603. doi: 10.1016/1054-3139(95)80074-3

Orejas, C., Rossi, S., Àurea, P., Eva, G., Gili, J. M., and Lippert, H. (2013). Feeding ecology and trophic impact of the hydroid Obelia dichotomain the Kongsfjorden (Spitsbergen, Arctic). Polar Biol. 36, 61-72. doi: 10.1007/s00300012-1239-7

Östman, C. (1997). Abundance, feeding behaviour and nematocysts of scyphopolyps (Cnidaria) and nematocysts in their predator, the nudibranch Coryphella verrucosa (Mollusca). Hydrobiologia 355, 21-28. doi: 10.1007/978-94-017-1907-0_3

Pierce, R. W., and Turner, J. T. (1992). Ecology of planktonic ciliates in marine food webs. Rev. Aquat. Sci. 6, 139-181.

Purcell, J. E. (1997). Pelagic cnidarians and ctenophores as predators: selective predation, feeding rates and effects on prey populations. Ann. Linst. Oceanogr. $73,125-137$.

Purcell, J. E. (2003). Predation on zooplankton by large jellyfish, Aurelia labiata, Cyanea capillata and Aequorea aequorea, in Prince William Sound, Alaska. Mar. Ecol. Prog. Ser. 348, 137-152.

Purcell, J. E. (2007). Environmental effects on asexual reproduction rates of the scyphozoan, Aurelia labiata. Mar. Ecol. Prog. Ser. 348, 183-196. doi: 10.3354/ meps07056

Purcell, J. E. (2009). Extension of methods for jellyfish and ctenophore trophic ecology to large-scale research. Hydrobiologia 616, 23-50. doi: 10.1007/s10750008-9585-8

Purcell, J. E., Hoover, R. A., and Schwarck, N. T. (2009). Interannual variation of strobilation by the scyphozoan Aurelia labiata in relation to polyp density, temperature, salinity, and light conditions in situ. Mar. Ecol. Prog. Ser. 375, 139-149. doi: 10.3354/meps07785

Ribes, M., Coma, R., and Gili, J. M. (1999). Heterogeneous feeding in benthic suspension feeders: the natural diet and grazing rate of the temperate gorgonian
Paramuricea clavata (Cnidaria: Octocorallia) over a year cycle. Mar. Ecol. Prog. Ser. 183, 125-137. doi: 10.3354/meps183125

Rossi, S., Ribes, M., Coma, R., and Gill, J. M. (2004). Temporal variability in zooplankton prey capture rate of the passive suspension feeder Leptogorgia sarmentosa (Cnidaria: Octocorallia), a case study. Mar. Biol. 144, 89-99. doi: 10.1007/s00227-003-1168-7

Rothschild, B. J., and Osborn, T. R. (1988). Small-scale turbulence and plankton contact rates. J. Plankton Res. 10, 465-474. doi: 10.1093/plankt/10.3.465

Schneider, G. (1989). Estimation of food demands of Aurelia aurita medusae populations in the Kiel Bight, Western Baltic. Ophelia 31, 17-27. doi: 10.1080/ 00785326.1989.10430848

Schneider, G., and Behrends, G. (1994). Population dynamics and the trophic role of Aurelia aurita medusae in the Kiel Bight and western Baltic. ICES J. Mar. Sci. 51, 359-367. doi: 10.1006/jmsc.1994.1038

Southward, A. J. (1955). Observations on the ciliary currents of the jellyfish Aurelia aurita L. J. Mar. Biol. Assoc. 34, 201-216. doi: 10.1017/ s0025315400027570

Thein, H., Ikeda, H., and Uye, S. (2012). The potential role of podocysts in perpetuation of the common jellyfish Aurelia aurita s.l. (Cnidaria: Scyphozoa) in anthropogenically perturbed coastal waters. Hydrobiologia 690, 157-167. doi: 10.1007/978-94-007-5316-7_12

Tsounis, G., Rossi, S., Laudien, J., Bramanti, L., Fernández, N., Gili, J. M., et al. (2006). Diet and seasonal prey capture rates in the Mediterranean red coral (Corallium rubrum L.). Mar. Biol. 149, 313-325. doi: 10.1007/s00227-005$0220-1$

Uye, S. (1982). Length-weight relationships of important zooplankton from the Inland Sea of Japan. J. Oceanogr. Soc. Jpn. 38, 149-158. doi: 10.1007/bf02110286

Uye, S. (2011). Human forcing of the copepod-fish-jellyfish triangular trophic relationship. Hydrobiologia 666, 71-83. doi: 10.1007/s10750-010-0208-9

Uye, S., and Shimauchi, H. (2005). Population biomass, feeding, respiration and growth rates, and carbon budget of the scyphomedusa Aurelia aurita in the Inland Sea of Japan. J. Plankton. Res. 27, 237-248. doi: 10.1093/plankt/fbh172

Uye, S., and Ueta, U. (2004). Recent increase of jellyfish populations and their nuisance to fisheries in the Inland Sea of Japan. Bull. Jpn. Soc. Fish. Oceanogr. 68, 9-19.

Wan, A. Y., and Zhang, G. T. (2012). Annual occurrence of moon jellyfish Aurelia $s p .1$ in the jiaozhou bay and its impacts on zooplankton community. Oceanol. Limnol. Sin. 43, 494-501.

Wang, N., Li, C. L., Liang, Y., Shi, Y. Q., and Lu, J. L. (2015). Prey concentration and temperature effect on budding and strobilation of Aurelia sp. 1 polyps. Hydrobiology 754, 125-134.

Wang, P. P., Zhang, F., Sun, S., Wang, W. C., Wan, A. Y., and Li, C. L. (2020). Experimental clearance rates of Aurelia coerulea ephyrae and medusae, and the predation impact on zooplankton in Jiaozhou Bay. J. Oceanol. Limnol. 4, $1256-1269$.

Wang, Y. T., and Sun, S. (2015). Population dynamics of Aurelia sp.1 ephyrae and medusae in Jiaozhou Bay, China. Hydrobiologia 754, 147-155.

Yu, Y., Zhang, W. C., Zhao, N., Sun, X. X., Zhang, C. X., Feng, M. P., et al. (2011). Annual variations in the abundance and biomass of planktonic ciliate in the jiaozhou bay. Oceanol. Limnol. Sin. 42, 690-701.

Conflict of Interest: The authors declare that the research was conducted in the absence of any commercial or financial relationships that could be construed as a potential conflict of interest.

Publisher's Note: All claims expressed in this article are solely those of the authors and do not necessarily represent those of their affiliated organizations, or those of the publisher, the editors and the reviewers. Any product that may be evaluated in this article, or claim that may be made by its manufacturer, is not guaranteed or endorsed by the publisher.

Copyright $\odot 2021$ Pengpeng, Fang, Dongjie and Song. This is an open-access article distributed under the terms of the Creative Commons Attribution License (CC BY). The use, distribution or reproduction in other forums is permitted, provided the original author(s) and the copyright owner(s) are credited and that the original publication in this journal is cited, in accordance with accepted academic practice. No use, distribution or reproduction is permitted which does not comply with these terms. 